\title{
Article
}

\section{Collaborative goal setting with adults attending physiotherapy at a specialist neuromuscular centre: is it always appropriate? A cross-sectional survey}

Hartley, S.E. and Stockley, Rachel

Available at http://clok.uclan.ac.uk/23924/

Hartley, S.E. and Stockley, Rachel ORCID: 0000-0003-4441-6860 (2016)

Collaborative goal setting with adults attending physiotherapy at a specialist neuromuscular centre: is it always appropriate? A cross-sectional survey.

Physiotherapy, 102 (4). pp. 320-326. ISSN 0031-9406

It is advisable to refer to the publisher's version if you intend to cite from the work. http://dx.doi.org/10.1016/j.physio.2015.10.014

For more information about UCLan's research in this area go to http://www.uclan.ac.uk/researchgroups/ and search for <name of research Group>.

For information about Research generally at UCLan please go to http://www.uclan.ac.uk/research/

All outputs in CLoK are protected by Intellectual Property Rights law, including Copyright law. Copyright, IPR and Moral Rights for the works on this site are retained by the individual authors and/or other copyright owners. Terms and conditions for use of this material are defined in the policies page. 


\section{Accepted Manuscript}

Title: Collaborative goal setting with adults attending physiotherapy at a specialist neuromuscular centre: Is it always appropriate? A cross-sectional survey

Author: S.E. Hartley R. Stockley

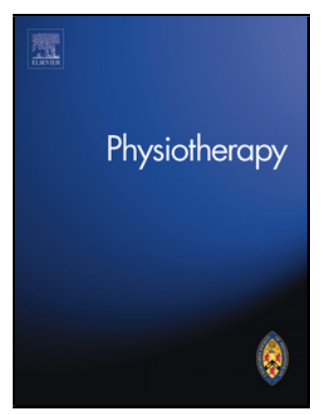

PII:

S0031-9406(15)03856-0

DOI: http://dx.doi.org/doi:10.1016/j.physio.2015.10.014

Reference: PHYST 877

To appear in: Physiotherapy

Received date: 23-2-2015

Accepted date: $30-10-2015$

Please cite this article as: Hartley SE, Stockley R, Collaborative goal setting with adults attending physiotherapy at a specialist neuromuscular centre: is it always appropriate? A cross-sectional survey, Physiotherapy (2015), http://dx.doi.org/10.1016/j.physio.2015.10.014

This is a PDF file of an unedited manuscript that has been accepted for publication. As a service to our customers we are providing this early version of the manuscript. The manuscript will undergo copyediting, typesetting, and review of the resulting proof before it is published in its final form. Please note that during the production process errors may be discovered which could affect the content, and all legal disclaimers that apply to the journal pertain. 
1

2

3

4

5 S.E. Hartley ${ }^{*}$, R. Stockley

6

7

8

9

10

11

12

13

14

15

16

17

18

19

20

21

22 *Corresponding author. Address: Department of Health Professions, Birley Building, Birley Fields Campus,

Collaborative goal setting with adults attending physiotherapy at

a specialist neuromuscular centre: is it always appropriate? A cross-sectional survey

(1)

Department of Health Professions, Birley Fields Campus, Manchester Metropolitan University, Manchester, UK fax: +44 (0)161 2476367.

E-mail address: s.hartley@mmu.ac.uk (S.E. Hartley). 


\section{Abstract}

27 Objectives Collaborative goal setting is an integral component of treatment planning for adults with neuromuscular disorders (NMD). However, due to the unique challenges for these individuals, identifying a process for goal setting that is advantageous for all can be problematic. This study aimed to evaluate collaborative goal setting at a specialist NMD centre, as reported by service users attending physiotherapy. It also aimed to generate discussion about collaborative goal setting and the practice of goal setting in adults with NMD in order to inform future practice.

Setting Specialist NMD community-based centre in the UK.

Participants One hundred and four adults with NMD who attended the centre.

Design Cross-sectional survey. Thematic and content analyses of goals set were performed alongside demographic data collection.

Results One hundred and four patients (34 females) with a range of neuromuscular conditions - including Becker, facioscapularhumeral, limb girdle, Duchenne and myotonic muscular dystrophies - completed the survey. Thirty-six respondents $(37 \%)$ stated that they had set goals with the physiotherapist, whilst 62 (63\%) stated that they had not set goals with the physiotherapist. Respondents' goals were grouped into four themes: symptom management, maintenance, improving physical condition, and learning to live with the condition.

Conclusions Readiness to take part in collaborative goal setting is unique to each individual. Physiotherapists need to be skilful in supporting adults with NMD through the goal-setting process until they are capable of sharing responsibility. Setting personal goals to improve emotional well-being may help to develop confidence to take more control of their situation, hence facilitating skills in self-management. 
51 Keywords: Neuromuscular disorders; Goal setting; Self-management; Long-term conditions 


\section{$<\mathrm{A}>$ Introduction}

Muscular dystrophy and its related neuromuscular disorders (NMD) are a frequently hereditary and diverse group of conditions that lead to abnormal muscle pathology with resultant muscle weakness and functional loss [1-5]. Although there is still no consensus on optimal physiotherapy for these disorders, and specific guidelines for their management are lacking, collaborative goal setting is considered to be an integral component of the rehabilitation process [6-9]. Collaborating, by working in partnership with patients to reach a consensus when setting goals, is also a requirement to meet professional standards for physiotherapy $[10,11]$.

There are many benefits to collaborative goal setting, including encouraging active participation of the patient in their management, providing shared outcomes for clinicians and patients to work towards, and facilitating patients to become more self-determining [12-17]. However, there are inconsistencies in its use amongst clinicians, and there is no defined approach for collaboration [6,18-21]. Patients also need to want, and be able, to participate in the process $[8,22,23]$.

Following a structured format when setting goals has been found to be more likely to engage patients and be more patient centred [14,24]. However, there is inconclusive evidence that structuring goal setting is more effective in achieving outcomes [9,24,25]. This suggests that the process alone cannot be credited for successful goal attainment. Indeed, the promotion of focused goals that are meaningful to the patient recognises the importance of the type of goals set $[10,17]$. If patients perceive that goals are relevant to them and have a worthwhile outcome, they are more likely to want to undertake and achieve these goals $[13,25]$. Consequently, in order to ensure that goals are significant to the patient, a partnership where patients are supported to take an active role in shaping these goals is likely to be essential $[17,21]$. However, collaborating in this way has been found to be problematic 
with differences between clinicians' and patients' expectations of roles and what can be achieved, and differing views on which goals are important or achievable [6,12,20,21,23]. This is even more complex for individuals with NMD as access to regular, specialist physiotherapy is often limited [26,27]. This means that the opportunity for adults with NMD to be guided through the goal-setting process, including identifying and monitoring appropriate goals, is likely to be inconsistent at best.

The catalyst for this article arose when data from a previous study, on the use of physiotherapy at a neuromuscular centre (NMC), found that many clients reported that they had not set goals with their physiotherapist [28]. When the authors collected the data, collaborative goal setting was usual physiotherapy practice at the NMC, but there was no set procedure amongst the physiotherapists for undertaking this process [29]. This study aimed to evaluate goal setting at the NMC, as viewed by service users who attend for physiotherapy. The intention was to gain insight into what may influence clients' reporting of goal setting, the type of goals set and how these are articulated by clients. A secondary aim of this study was to generate discussion around collaborative goal setting, and to consider the practice of goal setting in adults with NMD, in order to inform future practice.

\section{$<$ A $>$ Methods}

$<B>$ Participants

One hundred and thirty-three clients who attended for physiotherapy at the NMC between July and September 2010 were invited to participate.

\section{$<B>$ Design}

A prospective, cross-sectional survey of adult users of the NMC physiotherapy service was employed for this study. 


\section{$<B>$ Questionnaire}

Questions analysed for this study were part of a 13-item questionnaire that was developed to evaluate physiotherapy provision at the NMC. Two questions that asked if participants had set goals with their physiotherapist and if they were satisfied with the physiotherapy provision were used in order to gain some insight into goal setting at the $\mathrm{NMC}$, and if this influenced patient satisfaction with the physiotherapy received. Participants were also asked to record the goals that they had set with their physiotherapist. This information was collated with demographic details of all participants.

Following an initial pilot of the questionnaire with nine service users, the finalised questionnaire with detailed information about the study was given to all clients aged $\geq 18$ years when they attended for physiotherapy between July and September 2010. To ensure anonymity was maintained, each participant was asked to include a unique code on the questionnaire that was identifiable only to them, should they wish to withdraw their information.

\section{$<B>$ Data analysis}

All data collected were summarised and presented descriptively. The participants' goals were analysed thematically with open coding. An established framework for identifying goalsetting themes was not used as the researchers aimed to construct an interpretation of the nature of the goals from the participants' perspective rather than forcing them into preconceived categories [30]. Using this inductive process is a distinct approach to the quantitative methods used to describe the data initially [31]. By viewing the same social experience from different perspectives, the authors aimed to draw on the strengths of both methods in order to give a broader account of the goal-setting phenomenon [31,32]. 
Goals were initially coded independently by the two authors (SH and RS). Both read the goals repeatedly to gain an overview before writing a word or phrase by the side of each that reflected the nature of the goal prior to meeting to develop the themes. Goals that were deemed to be similar were grouped together into subthemes. Related subthemes were further combined to form the overarching theme of the goals that were set. Any initial differences in theme labelling were resolved through reflective dialogue by the authors, and the creation of diagrammatic representations of themes with their associated goals (see Table 1). A third researcher peer reviewed the process and corroborated the findings to improve credibility. Goals related to their overarching themes were subjected to content analysis [33].

\section{<insert Table 1 near here>}

\section{$<\mathrm{A}>$ Results}

In total, 133 clients accessed physiotherapy at the NMC during the survey period; of these, 125 agreed to take the questionnaire and eight declined. By the finalised date for return of questionnaires, 104 participants (78\%), had completed and returned the questionnaires by stamped addressed envelope or in person when attending the physiotherapy department. They had a range of neuromuscular conditions including Becker, facioscapularhumeral, limb girdle, Duchenne and myotonic muscular dystrophies; spinal muscular atrophy and CharcotMarie-Tooth disease. Of the 104 participants, there were 70 males and 34 females, with a median age of 45 years [interquartile range (IQR) 35 to 59 years]. Median time since diagnosis was 19.5 years (IQR 12 to 30 years). Seventeen participants (16\%) could complete all activities unaided, 54 participants (52\%) required some assistance to complete daily activities, $23(22 \%)$ required assistance for all tasks and $10(10 \%)$ could not complete most daily tasks (see [28] for more detailed demographic information). Of the participants that 
completed the questions on goal setting $(n=98), 36(37 \%)$ reported that they had set goals with the physiotherapist and $62(63 \%)$ stated that they had not set goals with the physiotherapist (see Table 2). Of those that answered the item on satisfaction $(n=101), 99$ (99\%) reported that they were satisfied with the physiotherapy provision and one $(1 \%)$ reported that they were not satisfied with the physiotherapy provision.

\section{<insert Table 2 near here>}

\section{$<B>$ Themes}

In total, 65 goals were identified by the participants. The goals were combined into four overarching themes: symptom management, maintenance, improving physical status and learning to live with the condition.

\section{$<C>$ Symptom management}

Twenty percent of goals (13/65) were concerned with ways to manage symptoms. These were mainly physical management, but also goals for helping with pain relief, particularly back pain. Although participants were asked to list the goals that they had set, these were not always articulated as goals in the same way that physiotherapists would be expected to communicate goals with their patients. This occurred in all categories, but especially symptom management. A number of goals were related to completion of exercises that they were to carry out and equipment that they were to use, rather than functional goals to work towards. For instance, one participant included 'active exercises with arm pedals' as a goal, and another participant wrote 'tilt table, for standing' as their current goal. Other participants just recorded one or two words under goals set. For example, one wrote 'stretches' and another wrote 'ball exercises'. Whilst these are likely to interlink with other themes, they 
were labelled together under 'symptom management' because they could all be related to helping the symptoms in one way or another.

\section{$<C>$ Maintenance}

Thirty-one percent of goals were related to maintenance (20/65). Goals that were identified under this theme were related to preserving the status quo in order to maintain their condition and prevent deterioration. Most goals were concerned with maintaining mobility, including joint range of motion as well as sustaining the ability to continue ambulation. Two maintenance-related goals were concerned with maintaining muscle strength.

\section{$<C>$ Improving physical condition}

Twenty-one percent (14/65) of goals were related to improving physical condition. These were primarily concerned with muscle strengthening, including core stability and goals for improving mobility, specifically joint flexibility, and standing time. Goals to improve the ability to perform an activity were also identified, as well as goals for losing weight.

\section{$<C>$ Learning to live with the condition}

The remaining $28 \%$ of goals $(18 / 65)$ were related to learning to live with the condition. These were mainly concerned with improving emotional state, including reducing depression, boosting morale and maintaining a positive outlook on life. Goals were also identified that referred to learning to cope with their problems, including pain management and confidence in performing activities. There were also a number of goals related to performing home exercise regimes.

\section{$<$ A $>$ Discussion}


This study aimed to describe and evaluate goal setting in clients attending the NMC for physiotherapy. The findings indicate that females and those over 65 years of age appeared to be most likely to report that they had set goals, irrespective of the time since diagnosis or how long they had been attending for physiotherapy. However, only $37 \%$ of participants reported that they had set goals with their physiotherapist, whilst $63 \%$ of participants were not aware of their participation in a goal-setting process. This is consistent with previous research that has found a disparity between clinicians' and patients' perceptions of goal setting, and the clinicians' belief that they had set goals with their patients which was not corroborated by the patients $[12,34]$. Whilst physiotherapists are practised in a formalised process of goal setting, many patients may have had limited or no previous experience in setting goals [34], so their interpretation of goals and the process of goal setting is likely to be different $[6,20,35]$. This was highlighted in this study when participants were asked to list the goals that they had set, as some listed equipment to use or how they were going to achieve the goal, rather than an actual goal to which they were working towards. Other patients omitted to write down their goals. It is not clear if this was because these participants were unable to articulate their goals or unable to recall the goals that had been set. However, a number of goals written by other participants were explicit and comprehensible, suggesting that there could be differences in the understanding or communication of goals. Indeed, how clinicians communicate goals has been found to be important to help patients to understand and share decisions when goals setting $[12,15]$. As each interaction with their patients will be unique, physiotherapists need to ensure that they are versatile in their language in order to ensure that goal setting is an inclusive process [12,34].

Many people with NMD face progressive physical changes; for many patients, these lead to a sense of self-loss until they accept their new circumstances $[26,36]$. As people with NMD go through these different stages, the capacity to deal with their situation and take 
control of their life varies $[4,26]$. Consequently, there may be occasions when wanting or having the emotional ability to take an active role in goal setting may be diminished $[8,22,23]$. Therefore, in this situation, it appears that collaborative goal setting is not desirable as patients only feel able to take a more passive role within the process [15,35]. Indeed, goal setting may not have been an important consideration for participants, as $99 \%$ reported that they were satisfied with the physiotherapy service they received regardless of whether or not they had reported setting goals with their physiotherapist.

Lloyd [23] identified a ‘continuum' for goal setting ranging from physiotherapist-led goals to patient-led goals, with collaborative goal setting lying somewhere in the middle. It appears that individuals' aptitude for goal setting will fluctuate along this spectrum, depending on where they are on their own life course and how they are coping with challenges $[23,37]$. As can be seen in this study, the highest numbers of goal setters were within the most independent (no assistance to perform functional tasks) and most dependent groups (unable to perform most tasks). It may be that the most independent individuals had not yet had to face life-changing situations. Conversely, the more dependent participants may have learnt ways to manage and cope with their situation, so were more capable of taking responsibility in goal setting $[23,26]$. This suggests that physiotherapists need to be adaptable when setting goals, being more attuned to where patients lie along the spectrum and their readiness to take part in a collaborative process [15,23]. Physiotherapists at the NMC are specialists in NMD and have, in many cases, developed close working relationships with their clients. This could indicate that they intuitively have a greater understanding of the goalsetting abilities of their clients, and so are responsive and adaptable to the current capability of their patients to collaborate in the goal-setting process. This could be investigated in future work by identifying physiotherapists' views and practices in collaborative goal setting in this patient group. 
As NMD is progressive in nature [1,2], many of the goals set were related to maintenance of an individual's condition, particularly with preserving mobility and staying ambulant. This is not surprising, as retaining independence has been found to be a particular worry for people with NMD [26,28].

However, the second highest number of goals were concerned with helping individuals to cope and live with their condition by improving their emotional state, including confidence building and performing home exercise programmes. Individuals who are confident with good psychological health are more likely to want and be able to take more accountability in planning their future [22,38]. Consequently, goals to improve coping and well-being are likely to facilitate the individual's ability to progress along the goal-setting spectrum, and enable them to take an active part in goal setting, thus providing them with an important tool for developing self-management skills $[15,16]$. Crucially, supporting individuals to regulate themselves in this way is now seen as an integral part of patient management for people with long-term conditions $[17,39,40]$. This may be particularly pertinent for many individuals with NMD who have limited access to specialist physiotherapy [26,27], and consequently need means to take care of themselves in the community. Whilst goal setting is an important element in the management of people with NMD, it appears to be essential to not only consider the type of goals set, but also to consider the evolving process of goal setting as individuals with NMD negotiate their path through life. Ways to translate this to the community setting, particularly for people who have restricted access to specialist physiotherapy, to guide individuals through a goal-setting process now need to be explored.

\section{$<B>$ Limitations}


This study had various limitations as, although there was a $78 \%$ response rate (104/133), only 36 participants claimed that they had set goals with the physiotherapist; this is an interesting finding, worthy of further research. Nonetheless, the small number of respondents who set goals and the use of a single specialist centre restricts the external validity of the findings, so future research is needed to corroborate these results. Further exploration of goal setting from the viewpoint of the physiotherapists at the NMC would also inform debate on the goalsetting process for this patient group.

The findings of this study describe aspects of goal setting and highlight potential issues with setting goals for people with NMD. They also promote debate around issues such as the role of collaborative goal setting for individuals with NMD, the type of goals to be set, and how goal setting can be optimised to improve the lives of people living with NMD in the community.

\section{$<\mathrm{A}>$ Conclusion}

The majority of respondents reported that they did not set goals; of those who did, goals centred around themes of symptom management, maintenance, improving physical status and learning to live with the condition.

Whilst it is recognised that physiotherapists undertake collaborative goal setting with their patients, this is not always actualised $[6,23,34]$. As there may be times when individuals are not ready to share decision making, collaborative goal setting may not always be appropriate. In these instances, physiotherapists could consider the optimum way to guide their patients along the goal-setting spectrum until they develop the capability to participate in the process. Equally, physiotherapists need to be versatile in their language so that patients with varied experiences of goal setting can make sense of and contribute to the process. It is likely that setting personal goals that help individuals to improve their emotional well-being 
will help to endow them with the confidence to take more control of their situation. Effective goal setting could therefore be a valuable resource for physiotherapists, not only to support people with NMD to take more responsibility in their own future planning, but to facilitate self-management skills so that individuals with NMD can learn to live a more independent life in the community.

Ethical approval: Ethical permission for the original study was gained from Manchester Metropolitan University, Department of Exercise and Sports Science Academic Ethics Committee [IPS approval code 11.02.10(i)].

Conflict of interest: None declared.

\section{$<\mathrm{A}>$ References}

[1] Hilton-Jones D, Turner M. Eliciting the history. In: Hilton-Jones D, Turner M, editors. Oxford textbook of neuromuscular disorders. First edn. Oxford: Oxford University Press; 2014. p. 3-5.

[2] Brown SC, Jimenez-Mallebera C. Biochemical and molecular basis of muscle disease. In: Karpati G, Hilton-Jones D, Bushby K, Griggs RC, editors. Disorders of voluntary muscle. Eighth edn. Cambridge: Cambridge University Press; 2010. p. 37-80.

[3] Emery AE. Muscular dystrophy. Third edn. Oxford: Oxford University Press; 2008. p. 1-3.

[4] Nierse C, Abma T, Horemans A, van Engelen B. Research priorities of patients with neuromuscular disease. Disabil Rehabil 2013;35:405-12.

[5] Winter Y, Schepelmann K, Spottke A, Claus D, Grothe C, Schroder R, et al. Health-related quality of life in ALS, myasthenia gravis and facioscapulohumeral muscular dystrophy. J Neurol 2010;257:1473-81. 
[6] Brown M, Levack W, McPherson K, Dean S, Reed K, Weatherall M, et al. Survival, momentum, and things that make me "me": patients 'perceptions of goal setting after stroke. Disabil Rehabil 2014;36:1020-6.

[7] Levack WMM, Dean SG, Siegert RJ, McPherson KM. Navigating patient-centered goal setting in inpatient stroke rehabilitation: how clinicians control the process to meet perceived professional responsibilities. Patient Educ Counsel 2011;85:206-13.

[8] Chouinard MC, Gagnon C, Laberge L, Tremblay C, Côté C, Leclerc N, et al. The potential of disease management for neuromuscular hereditary disorders. Rehabil Nurs 2009;34:118-26.

[9] Playford D, Siegert R, Levack W, Freeman J. Areas of consensus and controversy about goal setting in rehabilitation: a conference report. Clin Rehabil 2009;23:334-44.

[10] Chartered Society of Physiotherapy. Quality assurance standards for physiotherapy service delivery. London: Chartered Society of Physiotherapy; 2012.

[11] Health and Care Professions Council. HCPC standards of proficiency for physiotherapists. London: Health and Care Professions Council; 2013.

[12] Sugavanam T, Mead G, Bulley C, Donaghy M, van Wijck F. The effects and experiences of goal setting in stroke rehabilitation - a systematic review. Disabil Rehabil 2013;35:177-90.

[13] Davies N. Healthier lifestyles: behaviour change. Nurs Times 2011;107:20-3.

[14] Ashford S, Jackson D, Turner-Stokes L. Goal setting, using goal attainment scaling, as a method to identify patient selected items for measuring arm function. Physiotherapy 2015;101:88-94.

[15] Mudge S, Stretton C, Kayes N. Are physiotherapists comfortable with person-centred practice? An autoethnographic insight. Disabil Rehabil 2014;36:457-63.

[16] Jones F, Livingstone E, Hawkes L. Getting the balance between encouragement and taking over - reflections on using a new stroke self-management programme. Physiother Res Int 2013;18:91-9. 
[17] NHS England. Personalised care and support planning handbook: the journey to personcentred care. London: NHS England; 2015.

[18] Barnard R, Cruice M, Playford E. Strategies used in the pursuit of achievability during goal setting in rehabilitation. Qual Health Res 2010;20:239-50.

[19] Van der Weyer, RC, Ballinger, C.Playford ED. Goal setting in neurological rehabilitation: staff perspectives. Disabil Rehabil 2010;32:1419-27.

[20] Ferguson A, Worrall L, Davidson B, Hersh D, Howe T, Sherratt S. Talk about goals for aphasia therapy: a systemic functional analysis. J Int Res Commun Disord 2010;1:95-118.

[21] Rosewilliam S, Sintler C, Pandyan A, Skelton JR, Roskell CA. Is the practice of goal-setting for patients in acute stroke care patient-centred and what factors influence this? A qualitative study. Clin Rehabil 2015; doi: 10.1177/0269215515584167.

[22] Scobbie L, Dixon, D., Wyke, S., Goal setting and action planning in the rehabilitation setting: development of a theoretically informed practice framework. Clin Rehabil 2011;25:468-82.

[23] Lloyd A, Roberts AR, Freeman, JA. Finding a balance in involving patients in goal setting early after stroke: a physiotherapy perspective. Physiotherapy Res Int 2014;18:147-57.

[24] Levack WMM, Weatherall M, Hay-Smith EJC, Dean SG, McPherson K, Siegert RJ. Goal setting and strategies to enhance goal pursuit for adults with acquired disability participating in rehabilitation. Cochrane Database System Rev 2015;7:CD009727.

[25] Wade DT. Goal setting in rehabilitation: an overview of what, why and how. Clin Rehabil 2009;23:291-5.

[26] Hartley S, Goodwin P, Goldbart J. Experiences of attendance at a neuromuscular centre: perceptions of adults with neuromuscular disorders. Disabil Rehabil 2011;33:1022-32.

[27] All Party Parliamentary Group for Muscular Dystrophy. Access to specialist neuromuscular care: the Walton report. London: Muscular Dystrophy Campaign; 2009. p. 7-11. 
[28] Hartley S, Stockley R. It's more than just physical therapy: reported utilization of physiotherapy services for adults with neuromuscular disorders attending a specialist centre. Disabil Rehabil 2013;35:282-90.

[29] Neuromuscular Centre. Physiotherapy. Neuromuscular Centre. Available at: http://www.nmcentre.com/nmc/how-we-can-help-you/physiotherapy/overview/ [accessed 22.09.15]

[30] Elo S, Kyng H. The qualitative content analysis process. J Adv Nurs 2008;62:107-15.

[31] Robson C. Real world research. Third edn. Chichester: John Wiley and Sons Ltd; 2011. p. $162-4$.

[32] Teddlie C, Tashakkori A. Foundations of mixed methods research: integrating quantitative and qualitative approaches in the social and behavioural sciences. London: Sage Publications Inc.; 2009. p. 3-18.

[33] Hsieh HF, Shannon SE. Three approaches to qualitative content analysis. Qual Health Res $2005 ; 15: 1277-88$.

[34] Schoeb V, Staffoni L, Parry R, Pilnick A. "What do you expect from physiotherapy?": a detailed analysis of goal setting in physiotherapy. Disabil Rehabil 2014;36:1679-86.

[35] Rosewilliam S, Roskell C, Pandyan A. A systematic review and synthesis of the quantitative and qualitative evidence behind patient-centred goal setting in stroke rehabilitation. Clin Rehabil 2011;25:501-14.

[36] LaDonna K. A literature review of studies using qualitative research to explore chronic neuromuscular disease. J Neurosci Nurs 2011;43:172-82.

[37] Thompson A. The meaning of patient involvement and participation in health care consultations: a taxonomy. Soc Sci Med 2007;64:1297-310.

[38] Stewart D, Yuen T. A systematic review of resilience in the physically ill. Psychosomatics 2011;52:199-209. 
[39] King's Fund. Transforming the delivery of health and social care. London: King's Fund; 2012.

[40] Newbould J, Burt J, Bower P, Blakeman T, Kennedy A, Rogers A, et al. Experiences of care planning in England: interviews with patients with long term conditions. BMC Fam Pract 2012;13:1-9. 
Table 1

Themes and examplars of goals recorded by clients at the neuromuscular centre

\begin{tabular}{|c|c|c|}
\hline Theme & Subthemes & Examplar goals \\
\hline Maintenance & $\begin{array}{l}\text { Maintaining mobility } \\
\text { Maintaining muscle strength }\end{array}$ & $\begin{array}{l}\text { I. To try to arrest the deterioration of my condition from the effects of its } \\
\text { advance } \\
\text { II. To maintain my condition } \\
\text { I. Keep muscles supple by stretch exercises } \\
\text { II. To keep movement in limbs } \\
\text { I. To do Togu cushion exercises to maintain my trunk } \\
\text { II. To maintain muscle }\end{array}$ \\
\hline Symptom management & $\begin{array}{l}\text { Pain relief } \\
\text { Type of exercises } \\
\text { Equipment used }\end{array}$ & $\begin{array}{l}\text { I. Reduce back pain } \\
\text { II. Pain relief } \\
\text { I. Active exercises with arm pedals } \\
\text { II. Ball exercises } \\
\text { I. Standing frame } \\
\text { II. Equipment needed }\end{array}$ \\
\hline $\begin{array}{l}\text { Improving physical } \\
\text { condition }\end{array}$ & $\begin{array}{l}\text { Improve mobility } \\
\text { Muscle strengthening } \\
\text { Improve ability to carry out } \\
\text { activity } \\
\text { Weight loss }\end{array}$ & $\begin{array}{l}\text { I. Become more mobile } \\
\text { II. Flexibility increased } \\
\text { I. Strengthen core muscles using Togu cushion and exercises } \\
\text { II. To strengthen and stimulate muscles made weaker by poor use } \\
\text { I. Try to improve on exercises } \\
\text { II. Increase standing time } \\
\text { I. To lose weight for more mobility } \\
\text { II. Weight loss }\end{array}$ \\
\hline $\begin{array}{l}\text { Learning to live with the } \\
\text { condition }\end{array}$ & $\begin{array}{l}\text { Improve emotional state } \\
\text { Coping with the situation } \\
\text { Home exercise programme }\end{array}$ & $\begin{array}{l}\text { I. Overcome my depression with the help of exercises } \\
\text { II. Improve confidence when walking around with sticks } \\
\text { I. Learning to live and cope with my extra problems } \\
\text { II. Cope better with my pain } \\
\text { I. Exercises are set so I may help myself } \\
\text { II. Loads of exercises to do at home }\end{array}$ \\
\hline
\end{tabular}


Table 2

Frequency and percentage distributions of participant characteristics, satisfaction levels and responses to goal setting

\begin{tabular}{|c|c|c|c|c|}
\hline \multirow{2}{*}{ Questions asked } & \multirow{2}{*}{$\begin{array}{l}\text { No. of } \\
\text { participants } \\
n(\%) \\
\end{array}$} & \multirow{2}{*}{$\begin{array}{l}\text { No. of } \\
\text { respondents to } \\
\text { goal setting } \\
n(\%) \\
\end{array}$} & \multicolumn{2}{|c|}{ Set goals } \\
\hline & & & $\begin{array}{l}\text { Yes } \\
n(\%)\end{array}$ & $\begin{array}{l}\text { No } \\
n(\%)\end{array}$ \\
\hline \multicolumn{5}{|l|}{$\operatorname{Sex}(n=104)$} \\
\hline Male & $70(67)$ & $65(93)$ & $21(32)$ & $44(68)$ \\
\hline Female & $34(33)$ & 33 (97) & $15(46)$ & $18(55)$ \\
\hline \multicolumn{5}{|l|}{ Age (years, $n=104$ ) } \\
\hline 18 to 35 & $31(30)$ & $28(90)$ & $12(43)$ & $16(57)$ \\
\hline 36 to 50 & $28(27)$ & $28(100)$ & $8(29)$ & $20(71)$ \\
\hline 51 to 65 & $34(33)$ & $32(94)$ & $10(31)$ & $22(69)$ \\
\hline 66 to 85 & $11(11)$ & $10(91)$ & $6(60)$ & $4(40)$ \\
\hline \multicolumn{5}{|l|}{ Time since diagnosis (years, $n=104$ ) } \\
\hline 0 to 5 & $9(9)$ & $8(89)$ & $4(50)$ & $4(50)$ \\
\hline 6 to 15 & $32(31)$ & $31(97)$ & $12(39)$ & $19(61)$ \\
\hline 16 to 30 & $39(38)$ & $36(92)$ & $9(25)$ & $7(75)$ \\
\hline$\geq 31$ & $24(23)$ & $23(96)$ & $11(48)$ & $12(52)$ \\
\hline \multicolumn{5}{|l|}{$\begin{array}{l}\text { Can you complete most ADL? } \\
(n=104)\end{array}$} \\
\hline No assistance & $17(16)$ & $15(88)$ & $8(53)$ & $7(47)$ \\
\hline Some assistance for some tasks & $54(52)$ & $52(96)$ & $16(31)$ & $36(69)$ \\
\hline Assistance for all tasks & $23(22)$ & $22(96)$ & $6(27)$ & $16(73)$ \\
\hline Not able to complete most tasks & $10(10)$ & $9(90)$ & $6(67)$ & $3(33)$ \\
\hline \multicolumn{5}{|l|}{$\begin{array}{l}\text { How long have you been having } \\
\text { physiotherapy at the NMC? } \\
\text { (years, } n=102 \text { ) }\end{array}$} \\
\hline$>5$ years & $61(60)$ & $58(95)$ & $23(40)$ & $35(60)$ \\
\hline$>1$ and $<5$ years & $24(24)$ & $23(96)$ & $7(30)$ & $16(70)$ \\
\hline$<1$ year & $11(11)$ & $11(100)$ & $4(36)$ & $7(64)$ \\
\hline$>3$ and $<6$ months & $2(2)$ & $2(100)$ & $2(100)$ & $0(0)$ \\
\hline 1 to 3 months & $3(3)$ & $2(67)$ & $0(0)$ & $2(100)$ \\
\hline$<1$ month & $1(1)$ & $1(100)$ & $0(0)$ & $1(100)$ \\
\hline
\end{tabular}


Overall, are you satisfied with physiotherapy provision at the NMC?

( $n=101)$

\begin{tabular}{ccccc} 
Yes & $100(99)$ & $96(96)$ & $34(35)$ & $62(65)$ \\
No & $1(1.0)$ & $1(100)$ & $1(100)$ & $0(0)$ \\
\hline
\end{tabular}

$A D L$, activities of daily living; NMC, neuromuscular centre. 